\title{
BMJ Open Impact of comorbid conditions on outcomes of hip and knee replacement surgery: a systematic review and meta- analysis
}

Bélène Podmore, ${ }^{1,2}$ Andrew Hutchings, ${ }^{1,2}$ Jan van der Meulen, ${ }^{1,2}$ Ajay Aggarwal, ${ }^{1,2}$ Sujith Konan ${ }^{3}$

To cite: Podmore B, Hutchings A, van der Meulen J, et al. Impact of comorbid conditions on outcomes of hip and knee replacement surgery: a systematic review and meta-analysis. BMJ Open 2018;8:e021784. doi:10.1136/ bmjopen-2018-021784

- Prepublication history and additional material for this paper are available online. To view these files, please visit the journal online (http://dx.doi. org/10.1136/bmjopen-2018021784).

Received 19 January 2018 Revised 31 March 2018 Accepted 24 May 2018

\section{Check for updates}

${ }^{1}$ Department of Health Services Research \& Policy, London School of Hygiene \& Tropical Medicine, London, UK ${ }^{2}$ Clinical Effectiveness Unit, The Royal College of Surgeons of England, London, UK

${ }^{3}$ Orthopaedics and Trauma,

University College London

Hospitals NHS Foundation Trust, London, UK

Correspondence to

Bélène Podmore;

belene.podmore@Ishtm.ac.uk

\section{ABSTRACT}

Objective To systematically perform a meta-analysis of the association between different comorbid conditions on safety (short-term outcomes) and effectiveness (longterm outcomes) in patients undergoing hip and knee replacement surgery.

Design Systematic review and meta-analysis. Methods Medline, Embase and CINAHL Plus were searched up to May 2017. We included all studies that reported data to allow the calculation of a pooled OR for the impact of 11 comorbid conditions on 10 outcomes (including surgical complications, readmissions, mortality, function, health-related quality of life, pain and revision surgery). The quality of included studies was assessed using a modified Newcastle-Ottawa Scale. Continuous outcomes were converted to ORs using the Hasselblad and Hedges approach. Results were combined using a random-effects meta-analysis.

Outcomes The primary outcome was the adjusted OR for the impact of each 11 comorbid condition on each of the 10 outcomes compared with patients without the comorbid condition. Where the adjusted OR was not available the secondary outcome was the crude $\mathrm{OR}$.

Results 70 studies were included with $16(23 \%)$ reporting on at least 100000 patients and $9(13 \%)$ were of high quality. We found that comorbidities increased the shortterm risk of hospital readmissions (8 of 11 conditions) and mortality (8 of 11 conditions). The impact on surgical complications was inconsistent across comorbid conditions. In the long term, comorbid conditions increased the risk of revision surgery ( 6 of 11 conditions) and longterm mortality (7 of 11 conditions). The long-term impact on function, quality of life and pain varied across comorbid conditions.

Conclusions This systematic review shows that comorbidities predominantly have an impact on the safety of hip and knee replacement surgery but little impact on its effectiveness. There is a need for high-quality studies also considering the severity of comorbid conditions.

\section{INTRODUCTION}

Hip and knee replacement surgery, the surgical replacement of a joint, is one of the most successful and cost-effective
Strengths and limitations of this study

- This study went beyond published reviews by analysing the relative impact of individual comorbid conditions on multiple outcomes that relate to safety and effectiveness of hip and knee replacement surgery.

Further to previous studies, to allow for meta-analysis of all outcomes, continuous outcomes were converted to the corresponding OR using the Hasselblad and Hedges approach.

- The search was limited to include specific comorbidities and outcomes so studies may have been missed.

- To enable a meta-analysis of the multiple conditions and outcomes, comorbid conditions and outcomes were grouped together and may have compromised the validity of the conclusions.

interventions in medicine. ${ }^{1}$ It offers considerable improvement in function and quality of life. ${ }^{2}$ It is expected that the demand for hip and knee replacement will increase as the prevalence of hip and knee osteoarthritis rises due to increases in life expectancy. ${ }^{3}$

There has been increasing interest in identifying the risk factors for poor outcomes of elective joint replacement to be able to optimise patients and improve outcomes. Previous research has reported variation in the use of hip and knee replacement according to socioeconomic status, ${ }^{4}$ sex ${ }^{5}$ insurance status, ${ }^{6}$ ethnicity $^{7}$ and geography. ${ }^{8}$ This variation may be explained in part by the lack of consensus among clinicians about the clinical indications for joint replacement surgery. ${ }^{9}$

Comorbid conditions, conditions that are present in addition to the index condition but are unrelated to the latter, are on the rise around the world as more people are living with multiple morbidities. In a large US study using administrative data, $83.7 \%$ patients who had undergone hip or knee replacement had 
at least one comorbid condition. ${ }^{10}$ This is higher than in the general population where in 2012 only $49.8 \%$ of US adults had at least one comorbid condition. ${ }^{11}$ As the prevalence of people living with multiple morbidities increases with age, it is expected that the number of patients undergoing elective hip and knee replacement with at least one comorbid condition will increase. ${ }^{12}$

There have been a number of studies reporting the impact of comorbidity on outcomes after hip and knee replacement. ${ }^{13-15}$ There is little evidence, however, to which extent different individual comorbid conditions affect a variety of outcomes that relate not just to the safety of the surgery but also long-term outcomes such as quality of life after hip and knee replacement surgery. Previous systematic reviews on comorbid conditions and outcomes of hip and knee replacement have typically focused on individual comorbidities, ${ }^{16}$ specific outcomes,${ }^{17}$ process measures and cost, ${ }^{18}$ short-term outcomes following hip and knee replacement or the overall impact of composite comorbidity indices on outcomes. ${ }^{14}$

This study provides evidence of the impact of different individual comorbid conditions on a wide range of surgical outcomes, including short-term outcomes related to the 'safety' of the surgery and long-term outcomes related to the 'effectiveness' of the surgery.

The aim of this systematic review and meta-analysis was to synthesise the literature on the impact of different individual comorbid conditions on short-term and long-term outcomes of hip and knee replacement surgery.

\section{METHODS}

\section{Patient and public involvement}

This systematic review forms part of a wider piece of work investigating the access to and outcomes of hip and knee replacement surgery for patients with comorbidities. The protocol, including the systematic review, was reviewed by patient representatives on the National Institute for Health Research (NIHR) Collaboration for Leadership in Applied Health Research and Care (CLAHRC) North Thames Patient and Public Involvement committee. Their comments and feedback were incorporated in the protocol.

\section{Literature search}

A search of Medline, Embase and CINAHL Plus was conducted up to 31 May 2017 to identify studies written in English. Limitations were not placed on date. Search terms for hip and knee replacement were combined with search terms for health outcomes and search terms for 11 common comorbid conditions: heart disease, high blood pressure, stroke, leg pain due to poor circulation, lung disease, diabetes, kidney disease, diseases of the nervous system, liver disease, cancer and depression (see online supplementary information 1). The conditions were selected because they are the comorbid conditions that are routinely captured in the national Patient-Reported Outcome Measures (PROMs) programme for patients undergoing elective surgery in the English National Health Service and were considered relevant comorbidities in terms of outcome prediction. ${ }^{19}$ Where possible $\mathrm{MeSH}$ or index terms were used. All the titles, selected abstracts and full-text articles were reviewed for eligibility by two reviewers (BP, AA). Data extraction was conducted by $\mathrm{BP}$ and checked by $\mathrm{AH}$. Any disagreements were resolved by two reviewers (JvdM, AH). The reference lists of existing systematic reviews and included studies were also checked for additional eligible articles.

\section{Eligibility criteria and data extraction}

We included published full-text observational (either prospective or retrospective) studies in the English language that compared the outcomes of hip or knee replacement in patients with and without any of the 11 comorbid conditions. Studies were ineligible if they used a summary comorbidity index (eg, Charlson Comorbidity Index) or a single count of comorbidities because the aim of our study was to understand the impact of individual comorbid conditions. Studies, including other joint replacements, were only eligible if hip and/or knee replacement represented at least $90 \%$ of participants or if results were reported separately. Small studies, those with fewer than 100 participants, were excluded because hip and knee replacement are common procedures and the selected comorbid conditions are relatively common. Studies were ineligible if they failed to include at least one of the following outcomes: surgical complications, mortality, function, pain, health-related quality of life, hospital readmission and revision surgery.

Information on the study design, population and measures of association was extracted for eligible studies. Data were extracted on the participants (type of surgery), source of study data, the specific condition and the definition of the outcome for each reported association between a comorbid condition and outcome in a study (see online supplementary information 2). In addition, data were also extracted on the measure of association and its uncertainty and, for adjusted measures, the variables used in the adjusted analysis. Where possible, data on counts or means were used to calculate measures of association that had not been reported in the original study. Studies that indicated the statistical significance or otherwise of an association without reporting a quantitative metric were also recorded. Data were verified by a third reviewer (JvdM).

Ten categories of outcome were defined. Five shortterm outcomes, those occurring closest to 3 months after surgery, were: surgical complications, occurrence of venous thromboembolism (VTE), surgical site infections, readmission to hospital and mortality. Surgical complications were defined as the presence of any surgical complication as reported in a study. Two commonly reported surgical complications, VTE and infection, were also examined separately. Five long-term outcomes closest to 1 year postoperatively were: measures of hip or knee function, patient-reported quality of life, pain, revision 
Box 1 Study quality appraisal using a modified Newcastle-Ottawa Scale*

\section{Patient selection}

1. Was the cohort of patients undergoing hip or knee replacement surgery with comorbid conditions representative?

2. Was the reference cohort for patients without comorbid conditions drawn from the same community?

3. Was the presence of comorbid conditions adequately verified? (Yes=secure record or structured interview/self-report.)

4. Did the study demonstrate that the outcome of interest was not present at the start of the study?

5. Was the cohort or patients drawn from multiple communities?

\section{Comparability}

1. Did the study control for age and sex?

2. Did the study control for socioeconomic status and ethnicity?

\section{Outcome assessment}

1. Was the outcome of interest clearly defined? (Yes=study specific/ self-report, joint registry, $\mathrm{No}=$ administrative data.)

2. Was follow-up long enough for outcomes to occur? (Yes=short term minimum 30 days, long term minimum 6 months.)

3. Was follow-up adequate? (Yes=completed follow up $>90 \%$.)

*Studies were graded on an ordinal scoring scale with higher scores indicating studies of higher quality. A study could be awarded a maximum of one point for each numbered item except comparability items and the first item in outcome assessment, which could be awarded a maximum of two points for each numbered item.

surgery and mortality. We defined short-term outcomes as maximum 3 months and long-term outcomes as closest to 1 year after surgery because this reflected the definitions of outcomes used in the included studies and our judgement of events that reflect safety and effectiveness. For function and quality of life, they were only eligible for inclusion if analyses incorporated adjustment for preoperative scores or if similarity of preoperative scores was demonstrated. This was to ensure that the outcome captures the impact of surgery rather than any preoperative difference in score.

\section{Quality assessment}

The internal and external validity of the studies was appraised using the Newcastle-Ottawa Scale (NOS) ${ }^{20}$ that was modified to meet the requirements of this study (see box 1). Two reviewers (BP, AH) examined three items: patient selection, comparability of exposure and reference groups, and assessment of outcomes. For the comparability between the two groups, we focused on the following variables that previous studies have identified as predictors of various outcomes of hip and knee replacement surgery: age, sex, socioeconomic status and ethnicity. We added an extra item to assess the comparability of the cohorts on the basis of whether the cohort of patients were drawn from multiple centres or a single centre and whether the data sources were from specialist arthroplasty databases. The total possible score was 13. A study with a score of 11 or greater was considered high quality (see online supplementary information 3). This

\begin{tabular}{|c|c|c|}
\hline $\begin{array}{l}\text { Comorbid } \\
\text { condition }\end{array}$ & $\begin{array}{l}\text { No of } \\
\text { studies }\end{array}$ & $\begin{array}{l}\text { Included comorbid } \\
\text { conditions }\end{array}$ \\
\hline Cancer & 9 & $\begin{array}{l}\text { All cancers but if reported } \\
\text { separately cancer chosen in } \\
\text { preference to metastasis. }\end{array}$ \\
\hline Depression & 12 & All diagnoses of depression \\
\hline Diabetes & 41 & $\begin{array}{l}\text { Type } 2 \text { diabetes in preference } \\
\text { to type } 1 \text { diabetes. } \\
\text { Controlled diabetes in } \\
\text { preference to uncontrolled } \\
\text { diabetes. Diabetes without } \\
\text { complications in preference to } \\
\text { diabetes with complications. }\end{array}$ \\
\hline $\begin{array}{l}\text { Diseases of the } \\
\text { nervous system }\end{array}$ & 6 & $\begin{array}{l}\text { Alzheimer's disease, } \\
\text { Parkinson's disease, } \\
\text { dementia. }\end{array}$ \\
\hline Heart disease & 21 & $\begin{array}{l}\text { Heart disease but if reported } \\
\text { separately coronary heart } \\
\text { disease, coronary artery } \\
\text { disease or heart failure was } \\
\text { chosen. }\end{array}$ \\
\hline $\begin{array}{l}\text { High blood } \\
\text { pressure }\end{array}$ & 13 & High blood pressure. \\
\hline Kidney disease & 19 & $\begin{array}{l}\text { Renal disease but if reported } \\
\text { separately chosen chronic } \\
\text { kidney disease, chronic renal } \\
\text { disease or renal failure. }\end{array}$ \\
\hline Liver disease & 7 & $\begin{array}{l}\text { Liver disease but if reported } \\
\text { separately cirrhosis chosen. }\end{array}$ \\
\hline Lung disease & 18 & $\begin{array}{l}\text { Lung disease but if reported } \\
\text { separately chronic obstructive } \\
\text { pulmonary disorder chosen. }\end{array}$ \\
\hline Poor circulation & 7 & Peripheral vascular disease. \\
\hline Stroke & 12 & $\begin{array}{l}\text { Stroke or cerebrovascular } \\
\text { disease. }\end{array}$ \\
\hline
\end{tabular}

was to ensure we only included the highest quality studies and excluded those where there were concerns with cohort selection, confounding and outcome assessment.

\section{Quantitative data synthesis and meta-analysis}

An approach to data synthesis was chosen which allowed for a meta-analysis across multiple outcomes and conditions. This meta-synthesis approach has been used by a previous systematic review. ${ }^{21}$ The first stage of data synthesis involved selecting each study's measures of association to be included in the meta-analyses for each of the possible combinations of comorbid condition and outcome. Individual studies might have multiple measures for different combinations, for example, studies reporting multiple outcomes or different comorbid conditions. Studies might also have multiple measures for the same combination, for example, unadjusted and adjusted measures, measures for controlled and uncontrolled diabetes, or measures for hip and knee replacement surgery. Separate measures for hip and knee replacement were included 


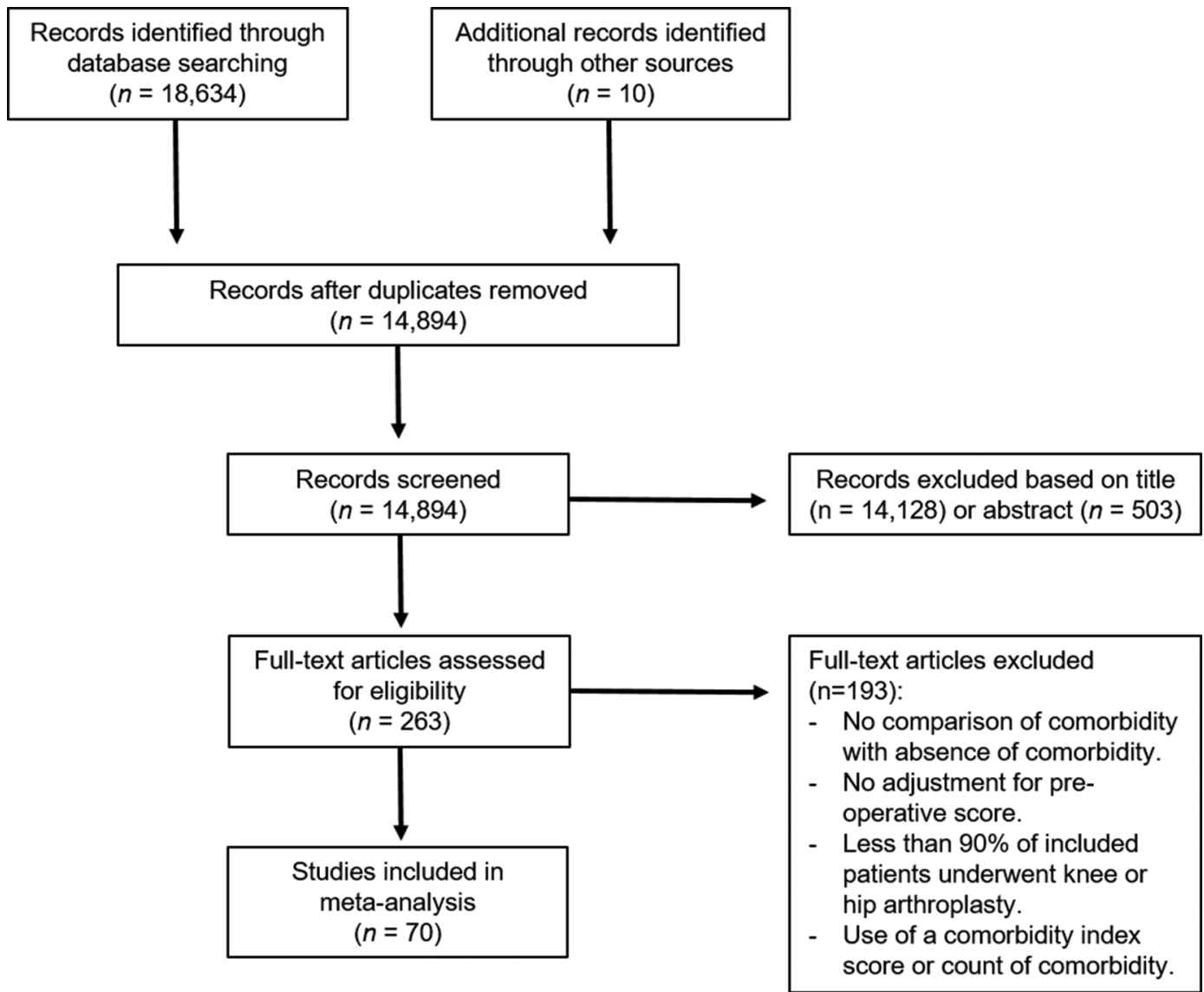

Figure 1 Flow chart.

in a combination's meta-analysis because they comprised different groups of participants. For other multiple measures, a single measure was selected for inclusion in a meta-analysis using the following criteria: adjusted over unadjusted measures, closer matching or more common subcategories of comorbid conditions for inexact mapping to the 11 selected conditions (see table 1), and closer matching to the timing (3 or 12 months) and definition of outcomes.

Most of the studies reported outcomes as ORs or it was possible to derive an OR. For studies reporting continuous outcomes the difference between means divided by the pooled SD (standardised mean difference) was converted to the corresponding OR using the Hasselblad and Hedges approach. ${ }^{22}$ If higher scores represented a good outcome then reciprocal values were used to ensure that ORs greater than 1 represented higher odds of a poor outcome. Where zero events precluded the calculation of an OR, each cell in the contingency table was inflated by adding $0.5^{23}$ to allow calculation of an OR.

We estimated the pooled OR for each combination of comorbid condition and outcome comprising two or more measures of association. ORs were computed such that a result greater than 1 indicates a higher odds of a worse outcome in patients with a specified comorbid conditions compared with patients without. We used a random-effects model as results were drawn from different populations. ${ }^{24}$ Pooled ORs by condition were plotted for each outcome. A sensitivity analysis was performed to assess the impact of the quality of the studies on the outcomes by comparing higher quality studies with studies of lower quality. The risk of publication bias was assessed using the graphical assessment of the funnel plot $^{23}$ on outcomes which were reported on by a greater than six studies. All statistical analyses were carried out using STATA V.14.

\section{RESULTS}

\section{Selected studies}

Full search results are represented in figure 1 . Of the 18644 studies identified in the search, we included 70 studies, ${ }^{25-94}$ which produced 314 results for individual comorbid conditions and outcomes of hip and knee replacement surgery. The 70 studies had a range of patients sample sizes from 122 to 8379490 . Sixteen (23\%) studies had at least 100000 patients. Twenty-six (37\%) studies reported combined hip and knee arthroplasties, $12(17 \%)$ studies reported on hip arthroplasties only, 24 (34\%) studies on knee arthroplasties and 9 (13\%) studies reported hip and knee arthroplasties separately. Forty $(70 \%)$ studies reported outcomes after primary hip or knee replacement. The 70 studies came from 13 different countries with $37(53 \%)$ coming from the USA. They were published between 1984 and 2017.

Overall, 43 (61\%) studies only looked at single comorbid conditions and $35(50 \%)$ only looked at single 


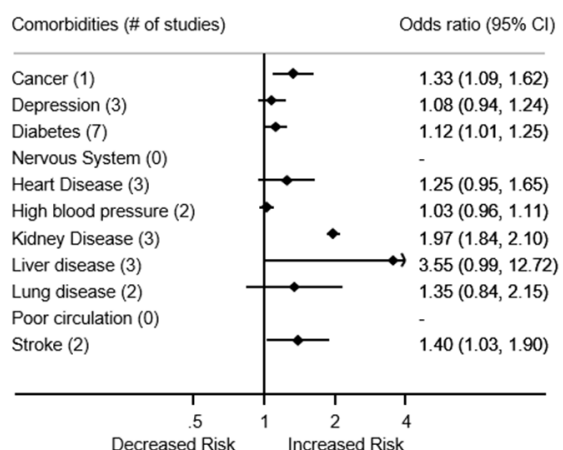

Readmissions

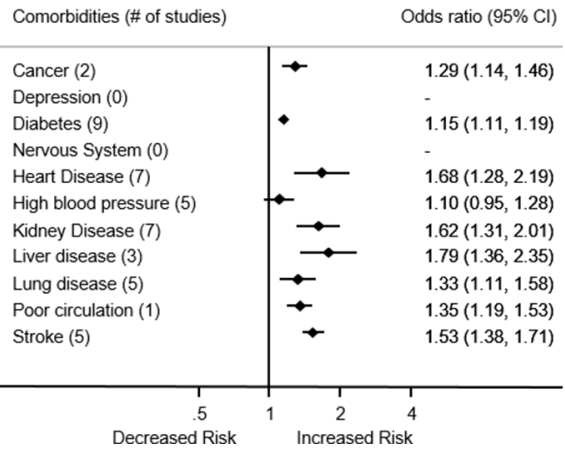

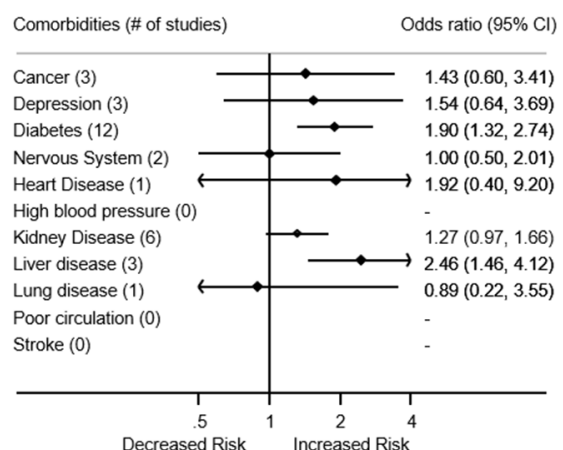

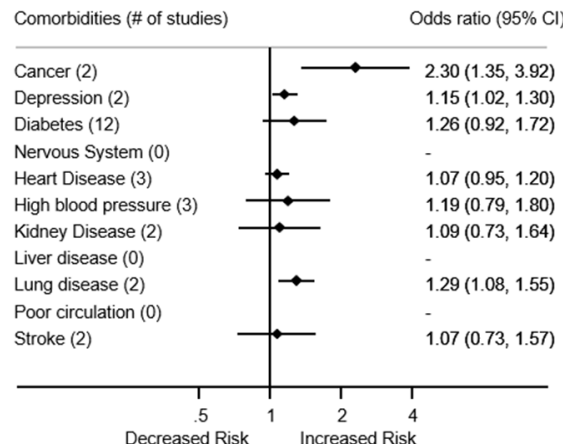

Short-term mortality

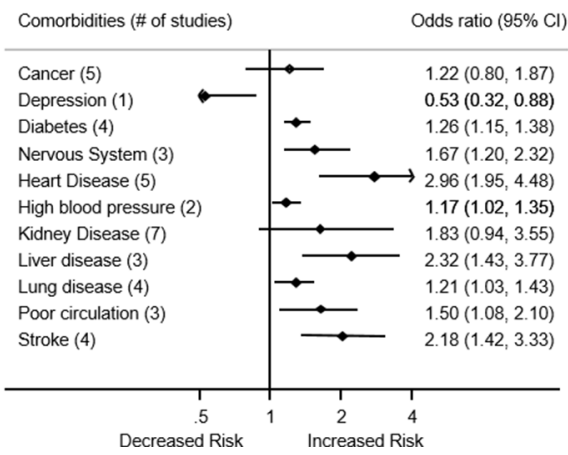

Figure 2 Forest plots of short-term outcomes.

outcomes. Sixty (86\%) studies investigated the association between comorbid conditions and surgical complications (including VTE and surgical site infections), and only $5(7 \%)$ quality of life. The comorbid condition that was most frequently studied was diabetes (41 studies), followed by heart disease (21 studies) and kidney disease (19 studies) (see table 1). The least frequently studied comorbid condition was diseases of the nervous system (six studies).

The median NOS score, the measure of study quality, was $10(6-13)$. Of the 70 , nine $(13 \%)$ studies met our predefined criteria for high quality of scores of greater than 11 . The majority of studies had a representative cohort of patients with a specified comorbid condition (56 studies) and adjusted for potential confounders such as age and gender (41 studies).

\section{Short-term outcomes}

\section{Surgical complications}

In this meta-analysis, 15 studies reported an OR for surgical complications in patients with comorbid conditions (see figure 2). The risk of surgical complications was significantly higher in patients with cancer (pooled OR 1.33, 95\% CI 1.09 to 1.62), diabetes (pooled OR $1.12,95 \%$ CI 1.01 to 1.25 ), kidney disease (pooled OR $1.97,95 \%$ CI 1.84 to 2.10 ) and stroke (pooled OR 1.40, $95 \%$ CI 1.03 to 1.90 ). No studies reported surgical complications in patients with nervous system diseases or poor circulation.

\section{Surgical site infections}

Twenty-seven studies reported on surgical site infections after surgery. Overall, surgical site infections tended to occur more frequently in patients with comorbid conditions but the likelihood was only significantly higher in patients with diabetes (pooled OR 1.90, 95\% CI 1.32, 2.74) and liver disease (pooled OR 2.46, 95\% CI 1.46 to 4.12) (see figure 2). No studies reported the likelihood of surgical site infections in patients with high blood pressure, poor circulation or stroke.

\section{Venous thromboembolism}

Eighteen studies reported the risk of VTE postoperatively. VTE was more likely in patients with cancer (pooled OR 2.30, 95\% CI 1.35 to 3.92), depression (pooled OR 1.15, 95\% CI 1.02 to 1.30 ) and lung disease (pooled OR 1.29, $95 \%$ CI 1.08 to 1.55 ). No studies reported the risk of VTE in patients with nervous system diseases, liver disease or poor circulation.

\section{Readmissions to hospital}

Sixteen studies looked at the presence of comorbid conditions and being readmitted to hospital within 90 days after surgery. Overall, the likelihood of readmissions to hospital was significantly higher for patients with comorbid conditions (8 out of 11) with the highest likelihood in patients with liver disease (pooled OR 1.79, 95\% CI 1.36 to 2.35 ) (see figure 2). No studies reported the likelihood of readmissions in patients with nervous system diseases or depression. 


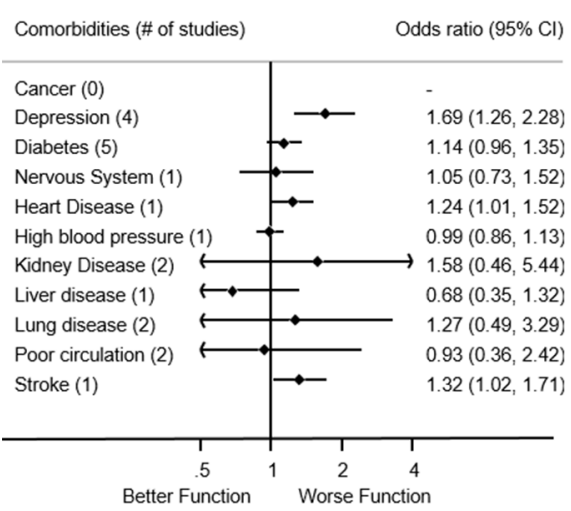

Revisions

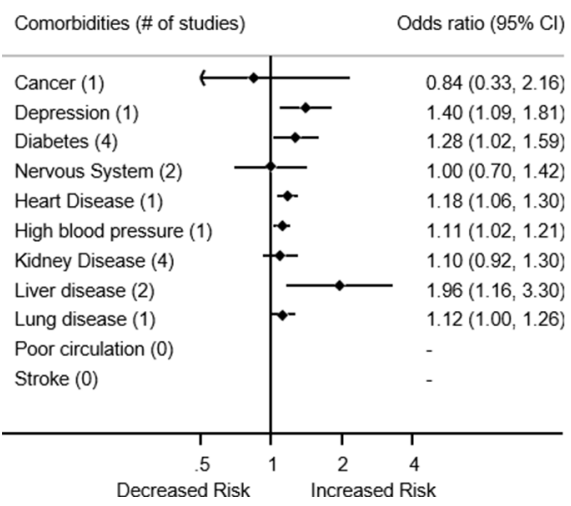

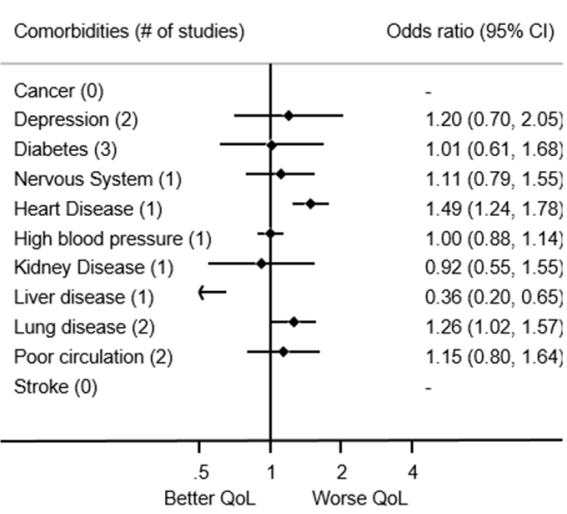

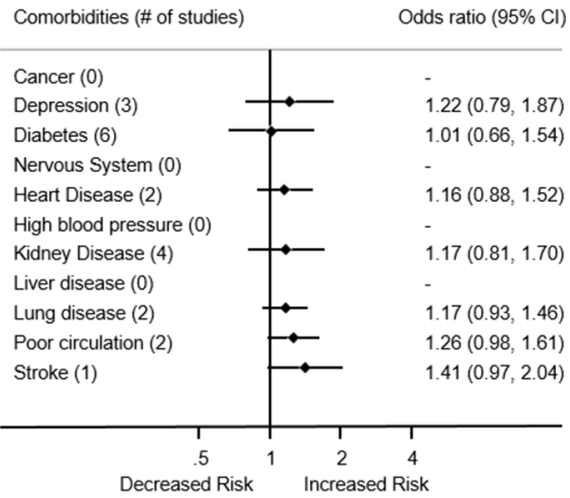

Long-term mortality

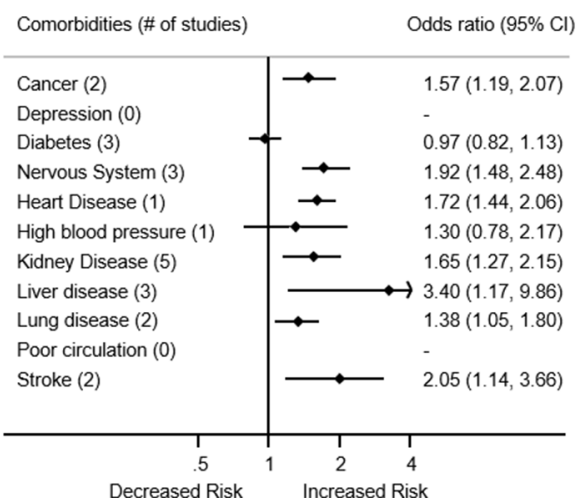

Figure 3 Forest plots of long-term outcomes.

\section{Short-term mortality}

Thirteen studies looked at mortality within 90 days after surgery. Overall, the likelihood of short-term mortality tended to be significantly higher in patients with comorbid conditions ( 8 out of 11) with the highest likelihood in patients with heart disease (pooled OR 2.96, 95\% CI 1.95 to 4.48) (see figure 2). In contrast, one study reported a significant lower likelihood of short-term mortality in patients with depression (pooled OR 0.53, 95\% CI 0.32 to 0.88$)$.

\section{Long-term outcomes}

Hip and knee function

Ten studies look at the impact of comorbid conditions on postoperative hip or knee function (see figure 3). Knee or hip function measures included: The Knee Society Knee Score, ${ }^{72}{ }^{78}$ Western Ontario and McMaster Universities Osteoarthritis Index (WOMAC) Score,${ }^{28} 2974$ Oxford Knee Score ${ }^{35}$ and Activities of Daily Living limitation. ${ }^{83} 8795$ The most frequently used measure was the WOMAC Score. Overall, the impact of comorbid conditions on function was variable. Patients with depression (pooled OR 1.69, 95\% CI 1.26 to 2.28), heart disease (pooled OR 1.24, $95 \%$ CI 1.01 to 1.52 ) and stroke (pooled OR $1.32,95 \%$ CI 1.02 to 1.71 ) had worse function after surgery. Postoperative function in patients with heart disease ${ }^{35}$ and stroke ${ }^{87}$ was each only reported on by one study. No studies investigated the postoperative function in patients with cancer.

\section{Health-related quality of life}

Five studies compared the improvement in quality of life 1 year after surgery in patients with comorbid conditions with those patients without comorbidities. Measures of quality of life included the Short Form- $12,{ }^{35}$ Short Form$36^{29} 7496$ and the Health Utilities Index. ${ }^{28}$ Overall, across comorbid conditions there was no consistent pattern. Quality of life was significantly worse for patients with heart disease (pooled OR 1.49, 95\% CI 1.24 to 1.78 ) and lung disease (pooled OR 1.26, 95\% CI 1.02 to 1.57 ). For patients with liver disease, quality of life was significantly better after surgery (pooled OR 0.36 , 95\% CI 0.20 to $0.65) .{ }^{35}$ Postoperative quality of life in patients with heart disease and liver disease was each only reported by one study. No studies investigated the postoperative quality of life in patients with cancer or stroke.

Pain

Ten studies reported on the association between comorbid conditions and pain. Five $(50 \%)$ studies looked at the outcome moderate to severe pain at 2 years and were studied by the same author. ${ }^{84} 85$ Other measures of pain included the WOMAC Pain Score ${ }^{28}$ and the Knee 
Society Pain Score. ${ }^{68} 72$ Overall, pain tended to be worse for patients with comorbid conditions but was not statistically significant. No studies investigated the postoperative pain in patients with cancer, nervous system diseases, liver disease or high blood pressure.

\section{Revision surgery}

Twelve studies reported on the likelihood of revision surgery in patients with comorbid conditions. Overall, revision surgery tended to be more likely in patients with comorbid conditions (6 out of 11) but the evidence remains weak. The pooled OR ranged from 1.11 (95\% CI 1.02 to 1.21) for patients with high blood pressure to 1.96 (95\% CI 1.16 to 3.30) for patients with liver disease. No studies reported the risk of revision surgery in patients with poor circulation or stroke.

\section{Long-term mortality}

Twelve studies reported the association between comorbid conditions and long-term mortality. Overall, the risk of long-term mortality tended to be higher for patients with comorbid conditions (7 out of 11). The pooled OR ranged from 1.38 (95\% CI 1.05 to 1.80 ) for lung disease to 3.40 (95\% CI 1.17 to 9.86 ) for liver disease (see figure 3). No studies investigated the risks of long-term mortality in patients with depression and poor circulation.

\section{Impact of comorbid conditions}

There is a lack of consistency across short-term and longterm outcomes by different comorbid conditions. In the short term, comorbidities had the most impact on readmissions to hospital and short-term mortality, but the impact on surgical complications was variable with most results not statistically significant. In the long term, comorbid conditions had the most impact on risk of revision surgery and long-term mortality. The impact on function and quality of life was inconsistent across comorbid conditions. The evidence for the impact of comorbid conditions on long-term outcomes was weaker than for short-term outcomes. Heart disease of all the included comorbid conditions had the most impact on both short-term and long-term outcomes with an increased likelihood of readmissions, short-term mortality, worse function, worse quality of life, revision surgery and longterm mortality.

\section{Publication bias}

We explored the possible impact of publication bias on outcomes: surgical complications, VTE, surgical site infections, readmissions, pain and mortality which had greater than six studies. This included studies in patients with diabetes (see figure 4) and kidney disease(see figure 5). The studies were not evenly distributed across both sides of the funnel plot. This asymmetry suggests that studies publishing negative effects may be missing. The impact of comorbidities on outcomes of hip and knee replacement may therefore be overestimated.

\section{Sensitivity analysis}

We performed a sensitivity analysis to estimate the robustness of the results by evaluating the effects of study quality (see online supplementary information 4). Overall, highquality studies pointed in the same direction as the lowerquality studies, although the latter generally reported larger effects. Higher-quality studies did not include studies reporting on the outcomes function, quality of life and pain, which suggest the evidence on long-term outcomes is poor compared with the evidence of the impact of comorbid condition on short-term outcomes. This may be largely because of the smaller sample size of these studies, the lack of adjustment for confounders and the lack of patient-reported outcomes in joint registries which focus primarily on surgical complications, mortality and revision rates.

\section{DISCUSSION}

\section{Main findings}

Overall, this meta-analysis demonstrates that patients with comorbid conditions are more likely to have a readmission and a higher short-term mortality in the early follow-up, but there is little evidence that patients benefit significantly less in terms of health-related quality of life, function and pain compared with patients with no comorbid conditions. In the short term, the impact on surgical complications was variable and mostly statistically insignificant. Patients with comorbid conditions tended to have a higher risk of revisions and long-term mortality but the available evidence was weak. There is some evidence of publication bias which may indicate an overestimation of the impact of comorbid conditions on outcomes. Given this, there is a need for high-quality studies in order to get a better understanding of the true impact of comorbidities on both short-term and long-term outcomes of hip and knee replacement.

Our study has implications for future research on clinical indication for joint replacement surgery. Clinicians should take into account prognostic factors that affect treatment effectiveness in their decision-making to refer or select patients for hip or knee replacement ${ }^{97}$ but due to the lack of clarity on clinical indication for hip and knee replacement, they are not able to do so effectively. ${ }^{98}$ Further research, specifically focusing on the long-term outcomes such as function, quality of life and pain and that stratify individual comorbidities according to severity are needed to provide clinicians with more evidence to guide their decision-making and management of patients with comorbid conditions and to minimise the variation and quality of care provided for this patient group.

\section{Quality of evidence}

Only $13 \%$ of the studies were graded as being of high quality. Poorer quality studies were typically less clear about the inclusion criteria for study patients and did not adjust for potential confounders such as age and gender. They were also based on either small single-site studies 

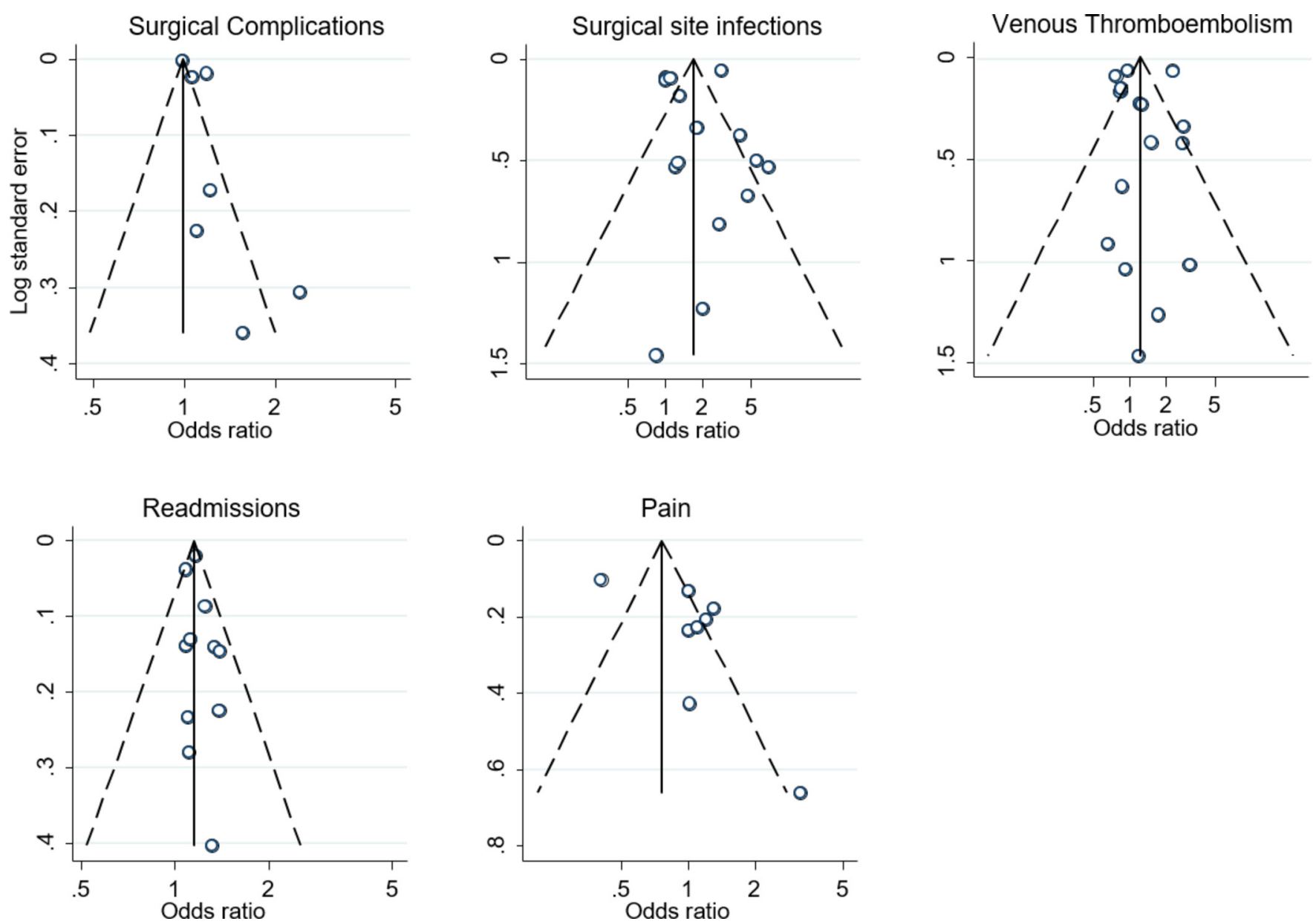

Figure 4 Funnel plot showing 95\% confidence limits for any surgical complications, surgical site infections, venous thromboembolism, readmissions to hospital and pain in patients with diabetes.

or large administrative data-based studies that use data sources that were not from specialist arthroplasty databases. Large administrative data-based studies greatly influenced the meta-analysis and thereby the limitations of these studies will therefore have a considerable influence on the validity of this meta-analysis. The higher quality studies primarily used joint registries and did not focus on patient-reported outcomes such as quality of life, function and pain.

Our sensitivity analysis showed that lower quality studies seem to overestimate the risk of short-term outcomes after hip and knee replacement in patients with comorbid conditions. Similarly, the evidence of reporting bias towards reporting positive findings may indicate an overestimation of the impact of comorbid conditions on outcomes of hip and knee replacement surgery. Due to the relatively small number of studies exploring the impact of each comorbid condition, it was not possible to fully explore the impact of publication bias and other factors that might cause heterogeneity.

It is important to consider, that patients included in the reported studies may represent a healthier population. Several studies have shown that patients are not accessing hip and knee replacement because clinicians are excluding complex and severe patients who are deemed too high risk for surgery. ${ }^{99}$ This may introduce selection bias which may lead to an underestimation of the true effect on the impact of comorbid conditions on outcomes of hip and knee replacement surgery.

\section{Relation to prior reviews}

Our study provides evidence that comorbid conditions have an impact on safety of the surgery but little impact on the effectiveness of the surgery in terms of quality of life, function and pain after hip and knee replacement surgery. There have been a number of earlier systematic reviews reporting the impact of comorbid conditions on outcomes after hip and knee replacement surgery. One systematic review and meta-analysis following elective total hip replacement in patients with diabetes found diabetes to be associated with a twofold increase risk of surgical site infections in line with our findings. ${ }^{16}$ Another one looking at the impact of comorbidity and length of stay and costs found limited evidence that comorbidities increase length of stay and costs compared with patients with no or fewer comorbidities. ${ }^{18}$ One systematic review looking at health-related quality of life in total hip and knee replacement reported that comorbid conditions was given as a reason for modest improvements in outcomes. ${ }^{17}$ This finding was only based on two studies 

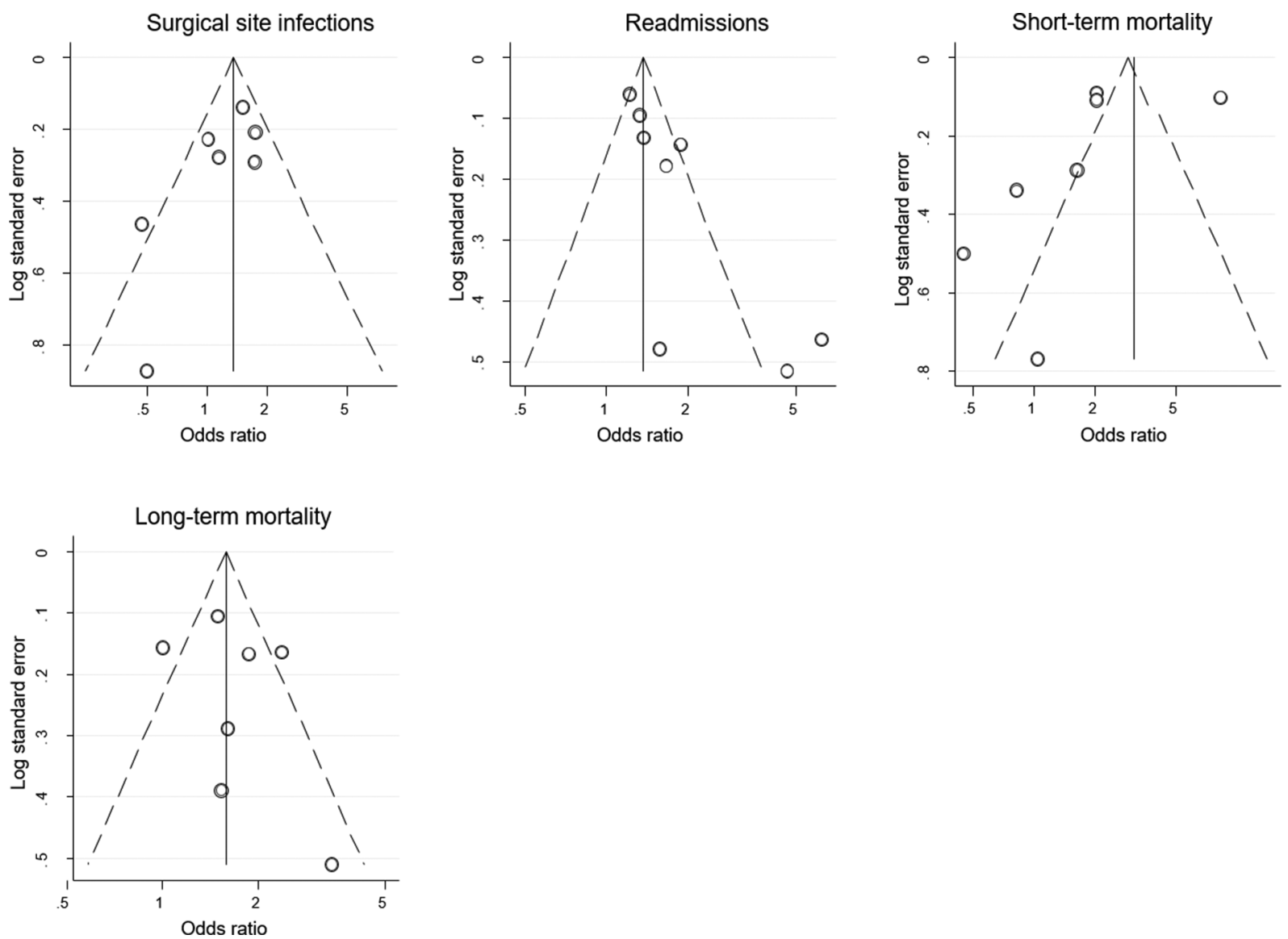

Figure 5 Funnel plot showing 95\% confidence limits for any surgical site infections, readmissions to hospital, short-term mortality and long-term mortality in patients with kidney disease.

both using composite comorbidity measures. Another systematic review looking at all preoperative predictors for outcomes for hip and knee replacement, however, demonstrated the inconsistency in study findings with seven studies reported a significant worse association between comorbid conditions and outcomes but six studies reported no significant association. ${ }^{14}$

\section{LIMITATIONS}

For some combinations of outcomes and comorbid conditions, there were no studies of impact or impact was only based on a single study. Only six studies focused on patients with diseases of the nervous system whereas over half of the studies we reviewed investigated outcomes in patients with diabetes. Similarly, short-term outcomes, particularly surgical complications, were commonly investigated but only five studies ${ }^{28} 29357496$ reported on quality of life outcomes and the results on pain were from two publications. ${ }^{84}{ }^{85}$ This highlights that evidence on short-term outcomes is stronger than evidence on long-term outcomes. Half of the studies were analyses of data collected in population-based administrative datasets. This may account for the relative scarcity of studies reporting on long-term outcomes such as quality of life or function that need patient-reported results.
We limited our review to studies with at least 100 patients and patients with the 11 comorbid conditions. Comorbid conditions that did not fit into the 11 categories that are captured in the PROMs programme for patients undergoing elective surgery in the English National Health Service were not included in this review. In addition, specific outcomes and patient-reported measures were not specified in the literature search so this may have resulted in the omission of some studies that met the inclusion criteria. We performed manual searches of relevant journals however and checked the references lists of all included studies and other systematic reviews, so we believe that any missed studies would not affect our conclusions significantly.

The scope of this review required the grouping of heterogeneous studies. Across all studies, there were differences in study populations, definitions of comorbid conditions and their severity, definitions of outcomes, particularly for patient-reported outcomes, and the constructs they are measuring and the timing of their measurement. To make the results comparable and to be able to conduct any form of meta-analysis, some comorbid conditions were grouped together, outcomes were categorised as short and long term, and continuous outcomes were converted to OR using the Hasselblad and Hedges approach. In addition, it was not possible to evaluate hip 
and knee replacement separately as 27 (38\%) studies reported on combined hip and knee arthroplasties.

In addition to variation in definitions of comorbid conditions, few included studies graded comorbid conditions according to severity which would have allowed a better understanding of their impact. For the few studies that reported results according to the severity of a comorbid condition, we included the most common severity subgroup, therefore excluding the most severe patients.

\section{CONCLUSION}

Clinicians should be aware of the short-term risks relating to the safety of the surgery in their management of patients with comorbid conditions. There is little evidence that patients with comorbid conditions benefit significantly less from hip and knee replacement in terms of quality of life, function and pain after surgery than patients without comorbid conditions. As a result comorbid conditions have an impact on safety but little impact on effectiveness of hip and knee replacement surgery. Future research should however consider the severity of comorbid conditions to better understand the impact of comorbid conditions on outcomes.

Contributors BP contributed to the study conception and design, literature screening, data extraction, analysis and interpretation of data, drafting of the manuscript and revision based on the comments of the coauthor. AH contributed to the study conception and design, literature screening, data extraction, analysis and interpretation of data and drafting of the manuscript. JvdM contributed to the study conception and design, literature screening, analysis and interpretation of data and critical revision of the manuscript. AA contributed to literature screening and the critical revision of the manuscript. SK contributed to the interpretation of data and the critical revision of the manuscript. The NIHR CLAHRC North Thames Patient and Public Involvement committee reviewed the protocol.

Funding This study was funded by the National Institute for Health Research (NIHR) Collaboration for Leadership in Applied Health Research and Care North Thames at Barts Health NHS Trust.

Disclaimer The views expressed are those of the authors and not necessarily those of the NHS, the NIHR or the Department of Health and Social Care.

Competing interests None declared.

Patient consent Not required.

Provenance and peer review Not commissioned; externally peer reviewed.

Data sharing statement No additional data are available.

Open access This is an open access article distributed in accordance with the Creative Commons Attribution Non Commercial (CC BY-NC 4.0) license, which permits others to distribute, remix, adapt, build upon this work non-commercially, and license their derivative works on different terms, provided the original work is properly cited, appropriate credit is given, any changes made indicated, and the use is non-commercial. See: http://creativecommons.org/licenses/by-nc/4.0/.

(C) Article author(s) (or their employer(s) unless otherwise stated in the text of the article) 2018. All rights reserved. No commercial use is permitted unless otherwise expressly granted.

\section{REFERENCES}

1. Liang MH, Cullen KE, Larson MG, et al. Cost-effectiveness of total joint arthroplasty in osteoarthritis. Arthritis \& Rheumatism 1986;29:937-43.
2. Aamodt A, Nordsletten L, Havelin LI, et al. Documentation of hip prostheses used in Norway: a critical review of the literature from 1996---2000. Acta Orthop Scand 2004;75:663-76.

3. Kurtz S, Ong K, Lau E, et al. Projections of primary and revision hip and knee arthroplasty in the United States from 2005 to 2030. J Bone Joint Surg Am 2007;89:780-5.

4. Neuburger J, Hutchings A, Black N, et al. Socioeconomic differences in patient-reported outcomes after a hip or knee replacement in the english national health service. $J$ Public Health 2013;35:115-24.

5. Jüni $P$, Low N, Reichenbach $S$, et al. Gender inequity in the provision of care for hip disease: population-based cross-sectional study. Osteoarthritis Cartilage 2010;18:640-5.

6. Schwarzkopf R, Phan DL, Hoang M, et al. Do patients with income-based insurance have access to total joint arthroplasty? J Arthroplasty 2014;29:1083-6.

7. Singh JA, Lu X, Rosenthal GE, et al. Racial disparities in knee and hip total joint arthroplasty: an 18-year analysis of national medicare data. Ann Rheum Dis 2014;73:2107-15.

8. Judge A, Welton NJ, Sandhu J, et al. Equity in access to total joint replacement of the hip and knee in England: cross sectional study. BMJ 2010;341:c4092.

9. Cobos R, Latorre A, Aizpuru F, et al. Variability of indication criteria in knee and hip replacement: an observational study. $B M C$ Musculoskelet Disord 2010;11.

10. Hustedt JW, Goltzer O, Bohl DD, et al. Calculating the cost and risk of comorbidities in total joint arthroplasty in the United States. $J$ Arthroplasty 2017;32:355-61.

11. Ward BW, Schiller JS, Goodman RA. Multiple chronic conditions among US adults: a 2012 update. Prev Chronic Dis 2014;11:E62.

12. Singh JA, Lewallen DG. Increasing obesity and comorbidity in patients undergoing primary total hip arthroplasty in the U.S.: a 13year study of time trends. BMC Musculoskelet Disord 2014;15:441.

13. Stürmer T, Dreinhöfer K, Gröber-Grätz D, et al. Differences in the views of orthopaedic surgeons and referring practitioners on the determinants of outcome after total hip replacement. J Bone Joint Surg Br 2005;87-B:1416-9.

14. Hofstede SN, Gademan MGJ, Vliet Vlieland TPM, et al. Preoperative predictors for outcomes after total hip replacement in patients with osteoarthritis: a systematic review. BMC Musculoskelet Disord 2016;17:212.

15. Hilton ME, Gioe T, Noorbaloochi S, et al. Increasing comorbidity is associated with worsening physical function and pain after primary total knee arthroplasty. BMC Musculoskelet Disord 2016;17:421.

16. Tsang ST, Gaston P. Adverse peri-operative outcomes following elective total hip replacement in diabetes mellitus: a systematic review and meta-analysis of cohort studies. Bone Joint $J$ 2013;95B:1474-9.

17. Ethgen $\mathrm{O}$, Bruyère $\mathrm{O}$, Richy $\mathrm{F}$, et al. Health-related quality of life in total hip and total knee arthroplasty. A qualitative and systematic review of the literature. J Bone Joint Surg Am 2004;86-A:963-74.

18. Olthof M, Stevens M, Bulstra SK, et al. The association between comorbidity and length of hospital stay and costs in total hip arthroplasty patients: a systematic review. J Arthroplasty 2014;29:1009-14.

19. Digital N. Patient reported outcome measures in england: data dictionary, 2016.

20. Wells G, Shea B. Newcastle-Ottawa quality assessment scale cohort studies. 2011 http://www.ohri.ca/programs/clinical_epidemiology/ oxford.asp

21. Linde K, Clausius N, Ramirez G, et al. Are the clinical effects of homoeopathy placebo effects? A meta-analysis of placebocontrolled trials. The Lancet 1997;350:834-43.

22. Hasselblad V, Hedges LV. Meta-analysis of screening and diagnostic tests. Psychol Bull 1995;117:167-78.

23. Egger M, Davey-Smith G, Altman D. Systematic reviews in health care: meta-analysis in context: John Wiley \& Sons, 2013.

24. DerSimonian R, Laird N. Meta-analysis in clinical trials. Control Clin Trials 1986;7:177-88.

25. Ackland GL, Moran N, Cone S, et al. Chronic kidney disease and postoperative morbidity after elective orthopedic surgery. Anesthesia \& Analgesia 2011;112:1375-81.

26. Adams AL, Paxton EW, Wang JQ, et al. Surgical outcomes of total knee replacement according to diabetes status and glycemic control, 2001 to 2009. J Bone Joint Surg 2013;87:481-7.

27. Aggarwal VK, Tischler EH, Post ZD, et al. Patients with atrial fibrillation undergoing total joint arthroplasty increase hospital burden. J Bone Joint Surg Am 2013;95:1606-11.

28. Amusat N, Beaupre L, Jhangri GS, et al. Diabetes that impacts on routine activities predicts slower recovery after total knee arthroplasty: an observational study. J Physiother 2014;60:217-23. 
29. Ayers DC, Franklin PD, Ploutz-Snyder R, et al. Total knee replacement outcome and coexisting physical and emotional illness. Clin Orthop Relat Res 2005;440:157-161.

30. Belmont PJ, Goodman GP, Rodriguez M, et al. Predictors of hospital readmission following revision total knee arthroplasty. Knee Surgery, Sports Traumatology, Arthroscopy 2016;24:3329-38.

31. Bolognesi MP, Marchant MH, Viens NA, et al. The impact of diabetes on perioperative patient outcomes after total hip and total knee arthroplasty in the United States. J Arthroplasty 2008;23:92-8

32. Browne JA, Sandberg BF, D'Apuzzo MR, et al. Depression is associated with early postoperative outcomes following total joint arthroplasty: a nationwide database study. J Arthroplasty 2014;29:481-3

33. Buller LT, Best MJ, Klika AK, et al. The influence of psychiatric comorbidity on perioperative outcomes following primary total hip and knee arthroplasty; a 17-year analysis of the national hospital discharge survey database. J Arthroplasty 2015;30:165-70.

34. Chan PK, Brenkel IJ, Aderinto J. The outcome of total hip arthroplasty in diabetes mellitus. $\mathrm{Br} J$ Diabetes Vasc Dis 2005;5:146-9.

35. Clement ND, MacDonald D, Burnett R, et al. Diabetes does not influence the early outcome of total knee replacement: a prospective study assessing the Oxford knee score, short form 12, and patient satisfaction. Knee 2013;20:437-41.

36. Cohen SM, Te HS, Levitsky J. Operative risk of total hip and knee arthroplasty in cirrhotic patients. J Arthroplasty 2005;20:460-6.

37. Courtney PM, Boniello AJ, Berger RA. Complications following outpatient total joint arthroplasty: an analysis of a national database. $J$ Arthroplasty 2017;32:1426-30.

38. Deegan BF, Richard RD, Bowen TR, et al. Impact of chronic kidney disease stage on lower-extremity arthroplasty. Orthopedics 2014;37:e613-e618.

39. Deleuran T, Vilstrup H, Overgaard S, et al. Cirrhosis patients have increased risk of complications after hip or knee arthroplasty. Acta Orthop 2015;86:108-113.

40. Dowsey MM, Choong PFM. Obese diabetic patients are at substantial risk for deep infection after primary TKA. Clinical Orthopaedics and Related Research ${ }^{\circledR}$ 2009;467:1577-1581.

41. Erkocak OF, Yoo JY, Restrepo C, et al. Incidence of infection and inhospital mortality in patients with chronic renal failure after total joint arthroplasty. J Arthroplasty 2016;31:2437-41.

42. Gandhi R, Razak F, Tso P, et al. Metabolic syndrome and the incidence of symptomatic deep vein thrombosis following total knee arthroplasty. J Rheumatol 2009;36:2298-301.

43. Gaston MS, Amin AK, Clayton RAE, et al. Does a history of cardiac disease or hypertension increase mortality following primary elective total hip arthroplasty? The Surgeon 2007;5:260-5.

44. Huddleston JI, Maloney WJ, Wang Y, et al. Adverse events after total knee arthroplasty: a national medicare study. J Arthroplasty 2009;24:95-100.

45. Hunt LP, Ben-Shlomo Y, Clark EM, et al. 45-day mortality after 467779 knee replacements for osteoarthritis from the National Joint Registry for England and Wales: an observational study. The Lancet 2014;384:1429-36.

46. Hunt LP, Ben-Shlomo Y, Clark EM, et al. 90-day mortality after 409096 total hip replacements for osteoarthritis, from the National Joint Registry for England and Wales: a retrospective analysis. The Lancet 2013;382:1097-104.

47. Iorio R, Williams KM, Marcantonio AJ, et al. Diabetes mellitus, hemoglobin a1c, and the incidence of total joint arthroplasty infection. J Arthroplasty 2012;27:726-9.

48. Inacio MCS, Pratt NL, Roughead EE, et al. Evaluation of three comorbidity measures to predict mortality in patients undergoing total joint arthroplasty. Osteoarthritis Cartilage 2016;24:1718-26.

49. Jain NB, Guller U, Pietrobon R, et al. Comorbidities increase complication rates in patients having arthroplasty. Clin Orthop Relat Res 2005;\&NA:232-8.

50. Jämsen E, Peltola M, Eskelinen A, et al. Comorbid diseases as predictors of survival of primary total hip and knee replacements: a nationwide register-based study of 96754 operations on patients with primary osteoarthritis. Ann Rheum Dis 2013;72:1975-82.

51. Jämsen E, Peltola M, Puolakka T, et al. Surgical outcomes of hip and knee arthroplasties for primary osteoarthritis in patients with Alzheimer's disease: a nationwide registry-based case-controlled study. Bone Joint J 2015;97-B:654-61.

52. Jämsen E, Puolakka T, Peltola M, et al. Surgical outcomes of primary hip and knee replacements in patients with Parkinson's disease: a nationwide registry-based case-controlled study. Bone Joint $J$ 2014;96-B:486-91.
53. Jørgensen CC, Knop J, Nordentoft M, et al. Psychiatric disorders and psychopharmacologic treatment as risk factors in elective fast-track total hip and knee arthroplasty. Anesthesiology 2015;123:1281-91.

54. Jørgensen CC, Madsbad S, Kehlet H. Postoperative morbidity and mortality in type-2 diabetics after fast-track primary total hip and knee arthroplasty. Anesthesia \& Analgesia 2015;120:230-8.

55. Judge A, Javaid MK, Arden NK, et al. Clinical tool to identify patients who are most likely to achieve long-term improvement in physical function after total hip arthroplasty. Arthritis Care Res 2012;64:881-9.

56. Kapoor A, Chew P, Silliman RA, et al. Venous thromboembolism after joint replacement in older male veterans with comorbidity. J Am Geriatr Soc 2013;61:590-601.

57. Kapoor A, Labonte AJ, Winter MR, et al. Risk of venous thromboembolism after total hip and knee replacement in older adults with comorbidity and co-occurring comorbidities in the nationwide inpatient sample (2003-2006). BMC Geriatr 2010;10:63.

58. Karam JA, Huang RC, Abraham JA, et al. Total joint arthroplasty in cancer patients. J Arthroplasty 2015;30:758-61.

59. Keswani A, Lovy AJ, Robinson J, et al. Risk factors predict increased length of stay and readmission rates in revision joint arthroplasty. $J$ Arthroplasty 2016;31:603-8.

60. Kildow BJ, Agaba P, Moore BF, et al. Postoperative impact of diabetes, chronic kidney disease, hemodialysis, and renal transplant after total hip arthroplasty. J Arthroplasty 2017;32:S135-S140.e1.

61. Kuo F-C, Lin P-C, Lu Y-D, Yd L, et al. Chronic kidney disease is an independent risk factor for transfusion, cardiovascular complication, and thirty-day readmission in minimally invasive total knee arthroplasty. J Arthroplasty 2017;32:1630-4.

62. Lee SW, Kumar Gn K, Kim TK. Unplanned readmissions after primary total knee arthroplasty in Korean patients: Rate, causes, and risk factors. Knee 2017;24.

63. Liao K-M, Lu H-Y, Hy L. A national analysis of complications following total hip replacement in patients with chronic obstructive pulmonary disease. Medicine 2016;95:e3182.

64. Marchant $\mathrm{MH}$, Viens NA, Cook C, et al. The impact of glycemic control and diabetes mellitus on perioperative outcomes after total joint arthroplasty. J Bone Joint Surg Am 2009;91:1621-9.

65. Martinez-Huedo MA, Villanueva M, de Andres AL, et al. Trends 2001 to 2008 in incidence and immediate postoperative outcomes for major joint replacement among Spanish adults suffering diabetes. European Journal of Orthopaedic Surgery \& Traumatology 2013;23:53-9.

66. Mazoch M, Barnes CL, Cooper K. Complications in diabetic patients undergoing revision total joint arthroplasty. Curr Orthop Pract 2016;27:296-302.

67. McCleery MA, Leach WJ, Norwood T. Rates of infection and revision in patients with renal disease undergoing total knee replacement in Scotland. J Bone Joint Surg Br 2010;92-B:1535-1539.

68. Meding JB, Reddleman K, Keating ME, et al. Total knee replacement in patients with diabetes mellitus. Clin Orthop Relat Res 2003;416:208-16.

69. Menendez ME, Park KJ, Barnes CL. Early postoperative outcomes after total joint arthroplasty in patients with multiple myeloma. $J$ Arthroplasty 2016;31:1645-8.

70. Miric A, Inacio MCS, Namba RS. The effect of chronic kidney disease on total hip arthroplasty. J Arthroplasty 2014;29:1225-30.

71. Miric A, Inacio MCS, Namba RS. Can total knee arthroplasty be safely performed in patients with chronic renal disease? Acta Orthop 2014:85:71-8.

72. Moon HK, Han CD, Yang IH, et al. Factors affecting outcome after total knee arthroplasty in patients with diabetes mellitus. Yonsei Med J 2008:49:129-37.

73. Pedersen AB, Mehnert F, Johnsen SP, et al. Risk of revision of a total hip replacement in patients with diabetes mellitus: a populationbased follow up study. J Bone Joint Surg Br 2010;92:929-34.

74. Pérez-Prieto D, Gil-González S, Pelfort X, et al. Influence of depression on total knee arthroplasty outcomes. J Arthroplasty 2014;29:44-7.

75. Radtke K, Tetzlaff T, Vaske B, et al. Arthroplasty-center related retrospective analysis of risk factors for periprosthetic joint infection after primary and after revision total hip arthroplasty. Technology and Health Care 2016;24:721-8.

76. Rajamäki TJ, Jämsen E, Puolakka PA, et al. Diabetes is associated with persistent pain after hip and knee replacement. Acta Orthop 2015;86:586-93

77. Rasouli MR, Menendez ME, Sayadipour A, et al. Direct cost and complications associated with total joint arthroplasty in patients with preoperative anxiety and depression. J Arthroplasty 2016;31:533-6.

78. Robertson F, Geddes J, Ridley D, et al. Patients with type 2 diabetes mellitus have a worse functional outcome post knee arthroplasty: a matched cohort study. Knee 2012;19:286-9. 
79. Sanders RD, Bottle A, Jameson SS, et al. Independent preoperative predictors of outcomes in orthopedic and vascular surgery: the influence of time interval between an acute coronary syndrome or stroke and the operation. Ann Surg 2012;255:901-7.

80. Seol Y-J, Yoon T-R, Lee D-H, et al. Outcome analysis of hip or knee arthroplasty in patients with cirrhotic liver disease. $J$ Orthop 2017:14:171-5

81. Sikora-Klak J, Zarling B, Bergum C, et al. The effect of comorbidities on discharge disposition and readmission for total joint arthroplasty patients. J Arthroplasty 2017;32:1414-7.

82. Singh JA. Effect of comorbidity on quality of life of male veterans with prevalent primary total knee arthroplasty. Clin Rheumatol 2009;28:1083-9.

83. Singh JA, Lewallen DG. Diabetes: a risk factor for poor functional outcome after total knee arthroplasty. PLoS One 2013;8:e78991.

84. Singh JA, Lewallen DG. Medical comorbidity is associated with persistent index hip pain after total hip arthroplasty. Pain Medicine 2013;14:1222-9.

85. Singh JA, Lewallen DG. Medical and psychological comorbidity predicts poor pain outcomes after total knee arthroplasty. Rheumatology 2013;52:916-23.

86. Singh JA, Lewallen DG. Underlying diagnosis predicts patientreported outcomes after revision total knee arthroplasty. Rheumatology 2014;53:361-6.

87. Singh JA, Lewallen DG. Cerebrovascular disease is associated with outcomes after total knee arthroplasty: a us total joint registry study. $J$ Arthroplasty 2014;29:40-3.

88. Singh JA, Lewallen DG. Depression in primary TKA and higher medical comorbidities in revision TKA are associated with suboptimal subjective improvement in knee function. BMC Musculoskelet Disord 2014;15:127.

89. Stundner O, Kirksey M, Chiu YL, et al. Demographics and perioperative outcome in patients with depression and anxiety undergoing total joint arthroplasty: a population-based study. Psychosomatics 2013;54:149-57.

90. Tiberi JV, Hansen V, El-Abbadi N, et al. Increased complication rates after hip and knee arthroplasty in patients with cirrhosis of the liver. Clinical Orthopaedics and Related Research ${ }^{\circledR}$ 2014;472:2774-8.

91. Vannini $P$, Ciavarella $A$, Olmi $R$, et al. Diabetes as pro-infective risk factor in total HIP replacement. Acta Diabetol Lat 1984;21:275-80.

92. Wang S, Zhao Y. Diabetes mellitus and the incidence of deep vein thrombosis after total knee arthroplasty: a retrospective study. $J$ Arthroplasty 2013;28:595-7.

93. Warth LC, Pugely AJ, Martin CT, et al. Total Joint Arthroplasty in Patients with Chronic Renal Disease: Is It Worth the Risk? J Arthroplasty 2015;30:51-4.

94. Zhao Z, Wang S, Ma W, et al. Diabetes mellitus increases the incidence of deep vein thrombosis after total knee arthroplasty. Arch Orthop Trauma Surg 2014;134:79-83.

95. Singh JA, Lewallen D, Age LD. Age, gender, obesity, and depression are associated with patient-related pain and function outcome after revision total hip arthroplasty. Clin Rheumatol 2009;28:1419-30.

96. Judge A, Arden NK, Batra RN, et al. The association of patient characteristics and surgical variables on symptoms of pain and function over 5 years following primary hip-replacement surgery: a prospective cohort study. BMJ Open 2013;3:e002453.

97. Santaguida PL, Hawker GA, Hudak PL, et al. Patient characteristics affecting the prognosis of total hip and knee joint arthroplasty: a systematic review. Can J Surg 2008;51:428-36.

98. Wright JG, Hawker GA, Bombardier C, et al. Physician enthusiasm as an explanation for area variation in the utilization of knee replacement surgery. Med Care 1999;37:946-56.

99. Dieppe PA. Inequalities in the provision of surgical interventions: whose responsibility? J Rheumatol 2011;38:401-2. 